\title{
Concentration-dependent duality of bFGF in regulation of barrier properties of human brain endothelial cells
}

Karolina Kriaučiūnaite ${ }^{1}$, Agnè Pociūte ${ }^{1}$, Aida Kaušyle ${ }^{1}$, Justina Pajarskienè ${ }^{1}$, Alexei Verkhratsky $^{1,2,3^{*}}$ and Augustas Pivoriūnas ${ }^{1 *}$

${ }^{1}$ Department of Stem Cell Biology, State Research Institute Centre for Innovative Medicine, LT01102, Vilnius, Lithuania

${ }^{2}$ Faculty of Biology, Medicine and Health, The University of Manchester, Manchester, M13 9PT, UK

${ }^{3}$ Achucarro Centre for Neuroscience, IKERBASQUE, Basque Foundation for Science, 48011

Bilbao, Spain

Send all correspondence to:

A. Pivoriūnas; email: augustas.pivoriunas@imcentras.lt

OR

A. Verkhratsky; email: Alexej.Verkhratsky@manchester.ac.uk 


\begin{abstract}
Multiple paracrine factors regulate barrier properties of human brain capillary endothelial cells (BCECs). Understanding precise mode of action of these factors remains a challenging task because of the limited availability of functionally competent BCECs and use of serum-containing medium. In the present study we employed defined protocol for producing BCECs from human inducible pluripotent stem cells. We found that autocrine secretion of basic fibroblast growth factor (bFGF) is necessary for the establishment a tight BCECs barrier, as revealed by measurements of transendothelial electric resistance (TEER). In contrast, exogenous bFGF in concentrations exceeding 4 $\mathrm{ng} / \mathrm{ml}$ inhibited TEER and proliferation of BCECs in a concentration-dependent manner. Exogenous bFGF did not significantly affect expression and distribution of tight junction proteins claudin-5, occludin and ZO-1. Treatment with FGF receptor blocker PD173074 $(15 \mu \mathrm{M})$ suppressed inhibitory effects of bFGF and induced nuclear translocation of protein ZO-1. Inhibition of phosphoinositide 3-Kinase (PI-3K) with LY294002 $(25 \mu \mathrm{M})$ significantly potentiated inhibitory effect of bFGF on TEER indicating that PI-3K signalling pathway partially suppress inhibitory effects of bFGF on TEER. In conclusion we show that autocrine bFGF secretion is necessary for the proper barrier function of BCECs, whereas exogenous bFGF suppresses barrier resistance in a concentrationdependent manner. Our findings demonstrate a dual role for bFGF in the regulation of BCEC barrier function.
\end{abstract}

Key words: Blood-brain barrier, human stem cells; endothelial cells; tight junctions; transendothelial electrical resistance 


\section{Introduction}

The blood brain barrier (BBB), formed by the continuous layer of tightly sealed specialised brain capillary endothelial cells (BCECs), separates brain parenchyma from the circulating blood [1]. Endothelial cells together with pericytes, astroglial cells and neurones form the neurogliovascular unit (NGVU) that regulates BBB and local cerebral blood flow [2,3]. At the cellular level, close contacts between BCECs are reinforced by tight and adherens junctions (TJ and AJ respectively) that seal the barrier. The BCECs also contact pericytes with which they share common basement membrane, while at the parenchymal side of the BBB astroglial endfeet plaster the basement membrane of capillaries or parenchymal basement membrane of larger calibre vessels [3]. The TJs and AJs by cementing intercellular contacts between adjacent BCECs prevent paracellular flux of hydrophilic molecules between the blood and the brain. Formation of these intercellular junctions is controlled by multiple paracrine signals deriving mostly from pericytes and astrocytes [4]. The AJs are formed by vascular endothelial (VE) cadherins connecting cytoskeletons of adjacent cells. Under normal conditions cortical actin bundles ascertain equal distribution of AJs between neighbouring cells, whereas permeability increasing factors, such as for example, thrombin, may induce actin remodelling leading to relocation of VE-cadherin complexes and AJs thus disrupting continuity and integrity of BBB [5,6]. The TJ proteins occludin, claudins and zonula occludens (ZO) are crucial regulators of paracellular permeability in the BBB. Cytoplasmic domains of occludin and claudins associate with ZO-1, -2 and -3 proteins, which localise to the cytoplasmic part of the plasma membrane and anchor TJ complexes to the actin filaments $[3,5]$.

Multiple paracrine mechanisms have been implicated in the regulation of expression and recruitment of TJ proteins to the junctional complexes. Astrocytes, for instance, secrete several factors regulating barrier properties of the $\mathrm{BBB}[7,8]$. These astrocytic factors include sonic hedgehog (SHH) [9,10], retinoic acid (RA) [11], ApoE4 and ApoE3 [12], angiopoetins [13], fibroblast growth factor (FGF) [6,14], and glia-derived neurotrophic factor (GDNF) [15] which all contribute to the astrocyte-endothelial, or astrocyte-pericyte-endothelial cells crosstalk. Revealing the mode of action of these paracrine factors is a task far from trivial. The in vivo models are not particularly suitable for the precise control and dynamic monitoring of paracrine factors at the BBB. On the other hand, until recently $\mathrm{BBB}$ in vitro models were limited to either primary, or immortalised BCECs, characterised by low transendothelial electrical resistance (TEER) [16,17]. In addition, most protocols used serum-containing medium, with its undefined components limiting consistency and reproducibility. Both human plasma derived serum and foetal bovine serum (FBS) represent rich and varying source of different growth factors and cytokines that may critically affect BCECs differentiation which further complicate in vitro studies of paracrine signalling.

Recent development of fully defined differentiation protocol [18] for producing BCECs from human inducible pluripotent stem cells (iPSCs) allows generation of monocultures with high TEER in the range of $\sim 4000 \Omega \cdot \mathrm{cm}^{2}$ that is close to the readings obtained in vivo [19]. In the present study we used this protocol to systematically test effects of basic fibroblast growth factor (bFGF) on the barrier properties of human BCECs monolayers. This reductionist approach has enabled identification of a novel role for bFGF in the regulation of barrier properties of BCECs. Autocrine bFGF secretion was necessary for the proper barrier function of BCECs whereas exogenous bFGF in concentrations exceeding $4 \mathrm{ng} / \mathrm{ml}$ inhibited TEER in a concentration-dependent manner. Our findings suggest the importance of bFGF signalling in regulation of BBB integrity. 


\section{Materials and methods}

\section{Human exfoliated deciduous teeth stem cells reprogramming into iPSCs}

Human exfoliated deciduous teeth stem cells (SHEDs) were derived from milk tooth according to the previously described protocol [20]. Material was collected under the approval of the Lithuanian Bioethics committee. SHEDs were maintained in DMEM-GlutaMAX medium (1 g/L glucose; Gibco), supplemented with $10 \% \mathrm{FBS}, 100 \mathrm{U} / \mathrm{ml}$ penicillin and $100 \mu \mathrm{g} / \mathrm{ml}$ streptomycin (all from Biochrom, Berlin, Germany) at $37{ }^{\circ} \mathrm{C}$ in a humidified $5 \% \mathrm{CO}^{2}$ atmosphere, medium was changed every 2-3 days. iPSCs from SHEDs were generated with Epi5 Episomal iPSC Reprogramming Kit and Neon Transfection System (both from Thermo Fisher Scientific, CA, USA) according to the manufacturer's protocol. On the 15th day of reprogramming N2B27 medium was switched to complete Essential 8 medium (E8; Thermo Fisher Scientific), which was then changed every two days. By 21st day, when iPSC colonies emerged, they were picked and expanded on plates coated with Matrigel (Corning, Cambridge, United Kingdom). Picked colonies were maintained in complete E8, medium was changed daily.

\section{iPSC maintenance}

In this study we used two iPSC lines. The MBE 2960 line [21] derived from healthy (age at biopsy 78, male) donor was provided by Prof. Alice Pébay, the University of Melbourne and Prof Alex Hewitt, the University of Tasmania. Second iPSC line was derived from SHEDs obtained from healthy human exfoliated deciduous teeth of children (female, 7 years old) at the State Research Institute Centre for Innovative Medicine. iPSCs were maintained in E8 medium supplemented with $50 \mathrm{U} / \mathrm{ml}$ penicillin and $50 \mu \mathrm{g} / \mathrm{ml}$ streptomycin, medium was changed every 24 hours. Cells were passaged upon reaching $80 \%$ confluence by washing twice with $0.5 \mathrm{mM}$ EDTA solution (Thermo Fisher Scientific), incubating in $0.5 \mathrm{mM}$ EDTA for 3-4 minutes at $37^{\circ} \mathrm{C}$, then detaching by stream of culture medium and subsequent plating onto Matrigel-coated plates in the fresh culture medium, supplemented with $5 \mu \mathrm{M}$ Y-27632 (Merck). iPSCs used in the following experiments were between passages 15 and 21 .

\section{iPSC differentiation to the brain endothelial cells}

Differentiation of iPSCs was based on the recently published protocol [18] with slight modifications. Briefly, iPSCs were seeded on Matrigel-coated plates at a density of $15800 \mathrm{cells} / \mathrm{cm}^{2}$ in E8 medium supplemented with ROCK inhibitor $10 \mu \mathrm{M}$ Y-27632. Differentiation was initiated after 24 hours by changing medium to Essential 6 (E6; Thermo Fisher Scientific). E6 medium was changed every 24 hours for 4 days. On the 5th day after seeding, medium was changed to human endothelial serum free medium (hESFM); supplemented with $20 \mathrm{ng} / \mathrm{ml} \mathrm{bFGF}$ (both from Thermo Fisher Scientific), $10 \mu \mathrm{M}$ retinoic acid (Merck Darmstadt, Germany) and 0.25x B-27 (Thermo Fisher Scientific). After 48 hours the same medium was changed again. The next day cells were subcultured: washed with PBS (Biochrom) once and subsequently incubated with Accutase (BD Biosciences) for 10 - $20 \mathrm{~min}$. The obtained cell suspension was centrifuged at $300 \mathrm{~g}$ for $3 \mathrm{~min}$. Cells were resuspended in hESFM medium supplemented with 0.25x B-27 (Thermo Fisher Scientific), 50 $\mathrm{U} / \mathrm{ml}$ penicillin and $50 \mu \mathrm{g} / \mathrm{ml}$ streptomycin (further - BCECs culture medium), then seeded onto polyester membrane Transwell inserts $\left(0.33 \mathrm{~cm}^{2}, 0.4 \mu \mathrm{m}\right.$ pore size; Corning) coated with a mixture of $400 \mu \mathrm{g} / \mathrm{ml}$ collagen IV and $100 \mu \mathrm{g} / \mathrm{ml}$ fibronectin (both from Merck). 


\section{BCEC treatments}

1 day after subculturing on Transwell filters medium was changed and various growth factors and pharmacological agents were added (Fig. 1a); after 3 days of further cultivation with these agents the TEER was measured (see Fig. 1a for experimental design). Immediately after these measurements cells were fixed for immunocytochemistry.

\section{Transendothelial electrical resistance (TEER) measurements}

TEER measurements [22] were performed on 3rd day of incubation with growth factors and (or) different inhibitors by using Millicell ERS-2 Electrical Resistance System (Merck-Millipore). Each insert was measured in three different locations. In order to calculate TEER $\left(\Omega \cdot \mathrm{cm}^{2}\right)$, the mean electrical resistance of cell-free insert was subtracted from the mean readings of insert with BCECs and then multiplied by the surface area of the insert.

\section{Immunocytochemistry and confocal microscopy}

After TEER measurements, culture medium was aspirated and cells were fixed with ice cold methanol-acetone solution $(1: 1)$ for $10 \mathrm{~min}$ at $-20{ }^{\circ} \mathrm{C}$, washed three times with PBS and blocked using $1 \%$ BSA-PBS solution for $30 \mathrm{~min}$ at room temperature (RT). Then incubated with primary antibodies (diluted in $1 \%$ BSA-PBS) against ZO-1 (1:33), claudin-5 (1:100) and occludin (1:50) (all from Thermo Fisher Scientific) at $4{ }^{\circ} \mathrm{C}$ overnight. Next, cells were washed three times with PBS and incubated with secondary antibodies diluted in PBS (1:1000 Alexa Fluor 594, Thermo Fisher Scientific) for 1 hour at RT, in the dark. Alternatively, cells were fixed with 4\% PFA for 20 min at RT, washed three times with PBS, permeabilised with $0.1 \%$ Triton X-100 for 15 min, washed three times with PBS again, blocked and incubated with Alexa Fluor 647-phalloidin conjugate (1:40; Life Technologies) for $1 \mathrm{~h}$ at RT in the dark. Then all membranes were washed 3 times and mounted on coverslips using an aqueous fluorescent mounting medium (DakoCytomation, Huddinge, Sweden). Samples were analysed with Leica TCS SP8 confocal microscope (Leica Microsystems, Mannheim, Germany), using Diode $405 \mathrm{~nm}$, DPSS $561 \mathrm{~nm}$ and a HeNe $633 \mathrm{~nm}$ lasers. Images were taken using $63 x$ oil immersion lens.

\section{ELISA}

The levels of bFGF autocrine secretion in BCECs monolayers were evaluated after 3 day incubation in hESFM medium. Cell culture supernatants were centrifuged at $10000 \mathrm{~g}$ for $10 \mathrm{~min}$ and stored $20{ }^{\circ} \mathrm{C}$ until further analysis. The levels of bFGF were quantified with human bFGF ELISA kit (BioLegend, Cat. Nr. 434309) according to the manufacturer's instructions. The colorimetric measurements $(\lambda=450 \mathrm{~nm}$, reference $\lambda=570 \mathrm{~nm})$ were performed using Asys UVM340 plate reader (Biochrom).

\section{Cell counting}

Images taken with confocal microscope were used for cell counting, which was performed manually using ImageJ program, multi-point tool. Only cell nuclei that entirely fit into a field of $185 \times 185$ $\mu \mathrm{m}$ were counted. 


\section{Statistics}

Differences between 2 groups were compared by Student's t-test. Data from all remaining experiments were compared by one-way ANOVA following Tukey's or Dunnett's post-test. All results were considered significant, at $p<0.05$. Statistical analysis was performed with Graph Pad Prism ${ }^{\circledR}$ software version 8.0.2 (Graph Pad Software, Inc., City, State, USA).

\section{Results}

Autocrine/paracrine signalling of bFGF is important for the maintenance of proper barrier function in $B C E C s$

After growing on the membraneous inserts for 3 days, the BCECs developed a functional barrier, as confirmed by TEER measurements: the TEER readouts ranged $3582 \pm 756 \Omega * \mathrm{~cm}^{2}(\mathrm{n}=19)$, which compares well with the in vivo readouts of $\sim 5000-6000 \Omega * \mathrm{~cm}^{2}$ [19]. The BCECs monolayers were also characterised by membrane-associated expression of major TJ proteins as revealed by immunochemistry (Fig. 1). Treatment of BCECs monolayers with selective inhibitor of bFGF receptor PD173074 $(15 \mu \mathrm{M}$ ) resulted in a significant decrease (by $53.83 \pm 22.28 \% ; n=8$ ) of TEER values (Fig. 1b). This decrease coincided with substantial reduction in the number of BCECs in monolayers (by $63.37 \pm 10.07 \%, \mathrm{n}=8$, Fig. 1c). These effects of PD173074 suggest constitutive secretion of bFGF which regulates barrier function through autocrine/paracrine stimulation of bFGF receptors. Indeed, ELISA assays confirmed this assumption by revealing bFGF in the culture media (Fig. 1d). At a sub-cellular level, inhibition of bFGF receptors with PD173074 induced redistribution of ZO-1 towards the cell nuclei; the immunolocalisation of claudin-5 and occludin, however, was not affected (Fig. 1e).

Exogenous bFGF inhibits TEER and increases BCEC proliferation in a concentration-dependent manner

Treatment of BCECs cultures with exogenous bFGF affected TEER in the concentration-dependent manner. At the lowest concentration of $0.8 \mathrm{ng} / \mathrm{ml}$ no changes in TEER were detected, however at higher concentrations TEER was progressively decreased (Fig. 2a). At $4 \mathrm{ng} / \mathrm{ml}$ bFGF the TEER was decreased by $65.29 \pm 6.75 \%$, at $8 \mathrm{ng} / \mathrm{ml}$ by $84.96 \pm 5.13$ and at $16 \mathrm{ng} / \mathrm{ml}$ by $97.06 \pm 1.55 \%(\mathrm{n}=6)$; the apparent $\mathrm{EC}_{50}$ being $3.2 \mathrm{ng} / \mathrm{ml}$. At the same time treatment of BCECs cultures with increasing doses of bFGF elevated number of cells in a similar concentration-dependent fashion (Fig. 2b). At $0.8 \mathrm{ng} / \mathrm{ml} \mathrm{bFGF}$ increased cell counts by $32.70 \pm 12.29 \%(\mathrm{n}=6)$, at $4 \mathrm{ng} / \mathrm{ml}$ by $73.30 \pm 22.56 \%(\mathrm{n}$ $=6)$, at $8 \mathrm{ng} / \mathrm{ml}$ by $95.00 \pm 14.64 \%(\mathrm{n}=6)$, and at $\mathrm{bFGF} 16 \mathrm{ng} / \mathrm{ml}$ by $99.00 \pm 16.06 \%$, $(\mathrm{n}=4)$; with the apparent $\mathrm{EC}_{50}$ of $2.2 \mathrm{ng} / \mathrm{ml}$.

\section{Specific inhibitor of bFGF receptor PD173074 antagonises effects of exogenous bFGF}

Treatment of BCECs with bFGF $(8 \mathrm{ng} / \mathrm{ml})$ suppressed TEER by $74.12 \pm 26.95 \%(\mathrm{n}=9)$, whereas combined treatment with bFGF and inhibitor of bFGF receptor PD173074 $(15 \mu \mathrm{M})$ suppressed TEER only by $39.53 \pm 21.55 \% \mathrm{n}=9$, indicating that PD173074 partially antagonised inhibitory effect of bFGF on the TEER readouts (Fig. 3a). Treatment of BCECs with bFGF $(8 \mathrm{ng} / \mathrm{ml}$ ) increased cell number by $95.00 \pm 15.86 \%(\mathrm{n}=9)$, whereas combined treatment with PD173074 decreased cell counts by $64.71 \pm 8.06 \%(\mathrm{n}=7)$ (Fig. 3b). Treatment of BCECs cultures with 
combination of bFGF and PD173074 affected neither expression nor distribution of claudin-5 and occludin (Fig. 3c). Exogenous bFGF also did not affect PD173074-induced nuclear accumulation of ZO-1 (Fig. 3c).

Effects of different combinations of bFGF, EGF, BMP-2 and CNTF on the barrier properties of $B C E C s$

We next investigated effects of bFGF in combination with different growth factors (GFs) on TEER in BCECs monolayers (Fig. 4). Treatment with combination of GFs consisting of bFGF (8 ng/ml), EGF $(10 \mathrm{ng} / \mathrm{ml})$, BMP-2 $(10 \mathrm{ng} / \mathrm{ml})$ and CNTF $(5 \mathrm{ng} / \mathrm{ml})$ significantly decreased TEER values in BCECs monolayers (Fig.4). After 3 days of incubation with GFs, TEER decreased up to 13.9 times when compared to untreated BCECs. All GF combinations containing bFGF strongly inhibited TEER (Fig. 4). The EGF potentiated inhibitory effect of bFGF, while EGF alone, or in combinations with other GFs decreased TEER only moderately. We also found that treatment with BMP-2, or CNTF alone as well as in combination, significantly increased TEER values in BCECs monolayers. Thus, bFGF strongly inhibits TEER also in the presence of other GFs.

\section{Inhibition of phosphoinositide 3-Kinase (PI-3K) potentiate inhibitory effect of bFGF on TEER}

Treatment of BCEC monolayers with PI-3K inhibitor LY294002 $(25 \mu \mathrm{M})$ alone down-regulated TEER by $47.63 \pm 23.53 \%(\mathrm{n}=8)$ (Fig. $5 \mathrm{a})$, while bFGF alone down-regulated TEER by $74.43 \pm$ $5.84 \%(\mathrm{n}=8)$ (Fig. 5a). Combination of bFGF $(8 \mathrm{ng} / \mathrm{ml})$ with LY294002 potentiated action of bFGF on TEER, decreasing it to $99.22 \pm 0.33 \%$ when compared to control $(n=8)$. Exposure to LY294002 inhibited proliferation of bFGF-treated and untreated BCECs by $32.50 \pm 19.69 \%(\mathrm{n}=8)$ and by $47.44 \pm 10.26 \%,(n=9)$, respectively (Fig. $5 b)$. Immunocytochemistry revealed fragmented staining patterns of occludin and ZO-1 of BCECs treated with bFGF and LY294002 (Fig. 5c).

Treatment with ROCK inhibitor Y-27632 $(10 \mu \mathrm{M})$ alone or in combination with bFGF did not significantly change TEER in BCEC monolayers. Neither it did affect proliferation (Fig. 6a,b); As expected, staining with phalloidin antibodies showed that blocking of ROCK significantly decreased formation of stress fibres in control and bFGF - treated cells (Fig. 7).

\section{Discussion}

In the present study we, for the first time, demonstrate a dose and source dependent duality of bFGF in the regulation of BCECs barrier integrity. First, we show that autocrine secretion of bFGF by BCECs is necessary for the proper barrier function; this action is achieved at low $(<4 \mathrm{ng} / \mathrm{ml})$ concentration of bFGF. Second, we demonstrate that exogenous bFGF in concentrations above 4 $\mathrm{ng} / \mathrm{ml}$ effectively suppresses TEER in BCEC monolayers (Fig. 8). Our findings suggest a novel mechanism for the effects of bFGF on the BCEC barrier function with potential implications in both physiological and pathological conditions.

The bFGF exerts pleiotropic effects in various tissues and acts as an important modulator of angiogenesis [23], CNS development [24], adult neurogenesis and neuroinflammation [25]. Several studies investigated effects of exogenous bFGF administration on the BBB integrity. All reports published hitherto demonstrated protective role of exogenous bFGF against BBB disruption occurring after intracerebral haemorrhage [6], traumatic brain injury [26], oxygen glucose 
deprivation [27,28] and mannitol-induced hyperosmotic shock [29]. In consequence, it was proposed that bFGF preserves AJs by suppressing the RhoA and ROCK by FGFR-induced activation of the PI3K-Akt-Rac1 signalling pathway [6]. Several in vitro studies [27,29] confirmed protective role of bFGF on the TEER of BCECs and are therefore in disagreement with our data. These discrepancies likely reflect differences in cell identities and in experimental design. More specifically, high concentration of bFGF $(2.5 \mu \mathrm{M}$, or $\sim 42.5 \mu \mathrm{g} / \mathrm{ml})$ has been used prior to TEER recordings in primary human brain microvascular endothelial cells (hBMEC) [27]. The study in question is also vague about how bFGF or PD173074 affected TEER values in hBMEC monolayers. Another investigation [30] used BCECs differentiated from human iPSCs according to the similar protocol as used by us. However, this protocol included platelet-poor plasma-derived serum which introduces an unknown and varying mixture of different growth factors; in contrast we applied a serum-free protocol [18].

We demonstrate that differentiated BCECs constitutively secrete bFGF and that autocrine/paracrine $\mathrm{bFGF}$ signalling is important for the maintenance of proper barrier resistance: inhibition of bFGF receptors with specific blocker leads to a significant disruption of barrier integrity reflected by a substantial $(\sim 54 \%)$ decrease in TEER values. Besides TEER maintenance, autocrine/paracrine bFGF signalling also positively regulates BCEC proliferation. Treatment with FGF receptor blocker PD173074 induced nuclear translocation of TJ protein ZO-1. In addition to being components of TJs and AJs, ZO proteins can shuttle between the cytoplasm and the nucleus and are involved in signal transduction and regulation of cell growth and proliferation [31]. Several reports demonstrated that nuclear accumulation of ZO-1 is inversely related to the maturity and integrity of cell-cell contacts [32,33]. These observations inspired the assumption that nuclear accumulation of $\mathrm{ZO}$ proteins represents a general response of epithelial and endothelial cells to different types of stress [31]. Our findings show similar redistribution of ZO-1 after inhibition of bFGF receptors in BCECs. We therefore suggest that inhibition of bFGF receptor decreases TEER at least partially through relocation of ZO-1 from TJs and AJs to the nuclei of BCECs.

Previous reports demonstrated that bFGF regulates BBB integrity through the PI-3K and ROCK signalling pathways $[6,26]$. Our data similarly indicate that PI-3K signalling contributes to regulation of BCEC barrier and BCEC proliferation (Fig. 8). Treatment with PI-3K blocker LY29402 significantly potentiated inhibitory effect of bFGF on TEER. It has been shown that PI$3 \mathrm{~K}$ signalling improves vascular permeability through Akt-FoxO pathway and subsequent upregulation of claudin-5 [34,35]. Akt is also a negative regulator of FoxO1 which can act as a transcriptional repressor of occludin [36]. Immunocytochemical labelling revealed fragmented staining patterns for occludin and ZO-1 in the membranes of BCECs treated with bFGF and LY29402 (Fig. 5c). LY294002 also induced moderate nuclear accumulation of ZO-1. Our results show that PI-3K signalling pathway partially antagonises inhibitory effects of bFGF on TEER.

ROCK promotes breakdown of intercellular junctions by inducing actomyosin contractility and relocation of AJs [5,6]. We demonstrate that inhibiting of ROCK with Y-27632 alone or in combination with bFGF affects neither BCEC proliferation nor TEER. We therefore conclude that in our experimental model ROCK signalling is not involved in the regulation of FGF-dependent effects on BCECs. Besides PI-3K-Akt, activated FGF receptor is coupled to RAS-MAPK, PLC $\gamma$ and STAT intracellular signalling pathways [37] that can mediate effects of bFGF.

Several studies demonstrated that bFGF can produce opposite effects depending on the concentration. Thus, bFGF can function as either a positive or a negative factor regulating in vitro 
adipogenesis by controlling activation of the ERK signalling pathway [38]. Another report demonstrated that, depending on bFGF concentration, non-canonical TGF $\beta$ can either restrict or promote FGFR signalling through ERK-dependent phosphorylation of adaptor protein FRS2 [39]. Further studies are necessary to elucidate detailed mechanisms by which different amounts of bFGF elicit opposite effects on the barrier properties of BCECs.

It is well known that injury and inflammation promote FGF-dependent angiogenesis [23,40]. We suggest that local fluctuations of bFGF may critically affect BBB integrity and permeability in vivo. What could be the main cellular source for the bFGF at the brain? Pericytes make close contacts and share common basement membrane with BCECs and therefore could represent potential source for exogenous bFGF. Indeed, pericytes strongly express bFGF and FGFR1 in peri-infarct areas after ischemic insult in mice [41]. Another report demonstrated that peripheral nerve pericytes modify $\mathrm{BBB}$ function and TJs partially through the secretion of bFGF [42]. Astrocytes represent another potential source of bFGF [43]. Different CNS pathologies have been associated with increased astroglial expression of bFGF [44]. Thus, acute stress or corticosterone administration induced bFGF secretion in hippocampal astrocytes of rats [45]. Astrocytes associated with white matter expressed high levels of bFGF during initial phase of remyelination after spinal cord lesions [46]. Of course, the results obtained in our in vitro study cannot be mechanically extrapolated to the complex in vivo contexts. However, they can be used as a starting point for more in-depth studies focusing on simultaneous in vivo monitoring of BBB permeability and local expression/secretion of bFGF during various pathologies.

In conclusion we show that autocrine bFGF secretion is necessary for the proper barrier function of BCECs whereas exogenous bFGF suppress it in a dose-dependent manner. Our findings demonstrate a dual role of bFGF in the regulation of BCEC barrier function.

\section{Acknowledgements}

This work was supported by the Global Grant measure (No. 09.3.3-LMT-K-712-01-0082). 


\section{Figure legends}

Fig. 1 bFGF constitutively secreted by BCECs supports the functional barrier through interacting with TJs and cell proliferation

a TEER in control conditions and after treatment with selective FGF receptor blocker PD173074 $(15 \mu \mathrm{M})$

b Number of BCECs in control conditions and after treatment with PD173074 (15 $\mu \mathrm{M})$

c bFGF levels measured with ELISA in supernatants from BCECs cultures

d Representative confocal images of BCEC cultures stained with antibodies against tight junction proteins claudin-5, occludin and ZO-1

Data are normalised to control values and expressed as $\% \pm$ S.D., ${ }^{*} p<0.001$, $* * p<0.0001, n=8$

Fig. 2 bFGF decreases TEER and increases number of BCECs in a concentration-dependent manner a TEER in control cultures and after treatment with different concentrations of bFGF $(0.8,4,8$ or $16 \mathrm{ng} / \mathrm{ml})$

b Number of BCECs in control conditions and after treatment with different concentrations of bFGF

Data are normalised to a control values and expressed as $\% \pm$ S.D., $* p<0.001, * * p<0.0001, n=$ 4-6

Fig. 3 Selective FGF receptor inhibitor PD173074 antagonises effects of exogenous bFGF

a TEER in control cultures and after treatment with bFGF $(8 \mathrm{ng} / \mathrm{ml})$ alone or in combination with PD173074 $(15 \mu \mathrm{M})$

b Number of BCECs in control cultures and after treatment with bFGF $(8 \mathrm{ng} / \mathrm{ml})$ alone or in combination with PD173074 $(15 \mu \mathrm{M})$

d Representative confocal images of BCECs cultures stained with antibodies against tight junction proteins claudin-5, occludin and ZO-1

Data are normalised to control values and expressed as $\% \pm$ S.D., $* p<0.001, * * p<0.0001, n=7$ 9

Fig. 4 TEER measurements in the presence of several GFs

a TEER readouts after treatment with bFGF $(8 \mathrm{ng} / \mathrm{ml})$, EGF $(10 \mathrm{ng} / \mathrm{ml})$, BMP-2 $(10 \mathrm{ng} / \mathrm{ml})$ and CNTF $(5 \mathrm{ng} / \mathrm{ml})$ alone or in combinations

b Table of descriptive statistics

TEER is expressed as $\Omega * \mathrm{~cm}^{2} \pm$ S.D., ${ }^{*} p<0.05, * * p<0.0001, n=2-3$ inserts

Fig. 5 PI 3-kinase inhibitor LY294002 decreases TEER and potentiates bFGF effects 
a TEER readouts after treatment with bFGF $(8 \mathrm{ng} / \mathrm{ml})$ alone or in combination with LY294002

b Number of BCECs in control conditions and after treatment with bFGF $(8 \mathrm{ng} / \mathrm{ml})$ alone or in combination with LY294002

c Representative confocal microscopy images of BCECs cultures stained with antibodies against tight junction proteins claudin-5, occludin and ZO-1

Data are normalised to control values and expressed as $\% \pm$ S.D., $* p<0.001, * * p<0.0001, n=6-$ 9

Fig. 6 ROCK inhibitor Y-27632 strengthened bFGF effect on TEER in BCECs, but had no effect by itself

a TEER readouts in control conditions and after treatment with bFGF $(8 \mathrm{ng} / \mathrm{ml})$ alone or in combination with Y-27632

b Number of BCECs in control conditions and after treatment with bFGF $(8 \mathrm{ng} / \mathrm{ml})$ alone or in combination with Y-27632

c Representative confocal images of BCEC cultures stained with antibodies against tight junction proteins claudin-5, occludin and ZO-1

Data are normalised to control values and expressed as $\% \pm$ S.D., ${ }^{*} p<0.001, * * p<0.0001, n=6$ 8

Fig. 7 ROCK inhibitor Y-27632 reduced stress fibre formation in untreated and bFGF-treated BCECs

Representative confocal microscopy images of BCEC cultures stained with antibodies against Factin.

Fig. 8 Dual action of bFGF on the brain endothelial cells barrier. See text for explanation

\section{References}

1. Wolburg H, Noell S, Mack A, Wolburg-Buchholz K, Fallier-Becker P (2009) Brain endothelial cells and the glio-vascular complex. Cell Tissue Res 335 (1):75-96. doi:10.1007/s00441-008-0658-9 2. Zhao Z, Nelson AR, Betsholtz C, Zlokovic BV (2015) Establishment and Dysfunction of the Blood-Brain Barrier. Cell 163 (5):1064-1078. doi:10.1016/j.cell.2015.10.067

3. Sweeney MD, Zhao Z, Montagne A, Nelson AR, Zlokovic BV (2019) Blood-Brain Barrier: From Physiology to Disease and Back. Physiol Rev 99 (1):21-78. doi:10.1152/physrev.00050.2017

4. Vardjan N, Parpura V, Verkhratsky A, Zorec R (2019) Gliocrine System: Astroglia as Secretory Cells of the CNS. Adv Exp Med Biol 1175:93-115. doi:10.1007/978-981-13-9913-8_4

5. Wettschureck N, Strilic B, Offermanns S (2019) Passing the Vascular Barrier: Endothelial Signaling Processes Controlling Extravasation. Physiol Rev 99 (3):1467-1525. doi:10.1152/physrev.00037.2018

6. Huang B, Krafft PR, Ma Q, Rolland WB, Caner B, Lekic T, Manaenko A, Le M, Tang J, Zhang JH (2012) Fibroblast growth factors preserve blood-brain barrier integrity through RhoA inhibition after intracerebral hemorrhage in mice. Neurobiol Dis 46 (1):204-214.

doi:10.1016/j.nbd.2012.01.008 
7. Cheslow L, Alvarez JI (2016) Glial-endothelial crosstalk regulates blood-brain barrier function. Curr Opin Pharmacol 26:39-46. doi:10.1016/j.coph.2015.09.010

8. Alvarez JI, Katayama T, Prat A (2013) Glial influence on the blood brain barrier. Glia 61 (12):1939-1958. doi:10.1002/glia.22575

9. Alvarez JI, Dodelet-Devillers A, Kebir H, Ifergan I, Fabre PJ, Terouz S, Sabbagh M, Wosik K, Bourbonniere L, Bernard M, van Horssen J, de Vries HE, Charron F, Prat A (2011) The Hedgehog pathway promotes blood-brain barrier integrity and CNS immune quiescence. Science 334 (6063):1727-1731. doi:10.1126/science.1206936

10. Podjaski C, Alvarez JI, Bourbonniere L, Larouche S, Terouz S, Bin JM, Lecuyer MA, SaintLaurent O, Larochelle C, Darlington PJ, Arbour N, Antel JP, Kennedy TE, Prat A (2015) Netrin 1 regulates blood-brain barrier function and neuroinflammation. Brain 138 (Pt 6):1598-1612. doi:10.1093/brain/awv092

11. Mizee MR, Nijland PG, van der Pol SM, Drexhage JA, van Het Hof B, Mebius R, van der Valk P, van Horssen J, Reijerkerk A, de Vries HE (2014) Astrocyte-derived retinoic acid: a novel regulator of blood-brain barrier function in multiple sclerosis. Acta Neuropathol 128 (5):691-703. doi:10.1007/s00401-014-1335-6

12. Bell RD, Winkler EA, Singh I, Sagare AP, Deane R, Wu Z, Holtzman DM, Betsholtz C, Armulik A, Sallstrom J, Berk BC, Zlokovic BV (2012) Apolipoprotein E controls cerebrovascular integrity via cyclophilin A. Nature 485 (7399):512-516. doi:10.1038/nature11087

13. Shen F, Walker EJ, Jiang L, Degos V, Li J, Sun B, Heriyanto F, Young WL, Su H (2011) Coexpression of angiopoietin-1 with VEGF increases the structural integrity of the blood-brain barrier and reduces atrophy volume. J Cereb Blood Flow Metab 31 (12):2343-2351. doi: $10.1038 /$ jcbfm.2011.97

14. Murakami M, Nguyen LT, Zhuang ZW, Moodie KL, Carmeliet P, Stan RV, Simons M (2008) The FGF system has a key role in regulating vascular integrity. J Clin Invest 118 (10):3355-3366. doi:10.1172/JCI35298

15. Igarashi Y, Utsumi H, Chiba H, Yamada-Sasamori Y, Tobioka H, Kamimura Y, Furuuchi K, Kokai Y, Nakagawa T, Mori M, Sawada N (1999) Glial cell line-derived neurotrophic factor induces barrier function of endothelial cells forming the blood-brain barrier. Biochem Biophys Res Commun 261 (1):108-112. doi:10.1006/bbrc.1999.0992

16. Eigenmann DE, Xue G, Kim KS, Moses AV, Hamburger M, Oufir M (2013) Comparative study of four immortalized human brain capillary endothelial cell lines, hCMEC/D3, hBMEC, TY10, and BB19, and optimization of culture conditions, for an in vitro blood-brain barrier model for drug permeability studies. Fluids Barriers CNS 10 (1):33. doi:10.1186/2045-8118-10-33

17. Dubey SK, Ram MS, Krishna KV, Saha RN, Singhvi G, Agrawal M, Ajazuddin, Saraf S, Saraf S, Alexander A (2019) Recent Expansions on Cellular Models to Uncover the Scientific Barriers Towards Drug Development for Alzheimer's Disease. Cell Mol Neurobiol 39 (2):181-209. doi:10.1007/s10571-019-00653-z

18. Neal EH, Marinelli NA, Shi Y, McClatchey PM, Balotin KM, Gullett DR, Hagerla KA, Bowman AB, Ess KC, Wikswo JP, Lippmann ES (2019) A Simplified, Fully Defined Differentiation Scheme for Producing Blood-Brain Barrier Endothelial Cells from Human iPSCs. Stem Cell Reports 12 (6):1380-1388. doi:10.1016/j.stemcr.2019.05.008

19. Butt AM, Jones HC, Abbott NJ (1990) Electrical resistance across the blood-brain barrier in anaesthetized rats: a developmental study. J Physiol 429:47-62.

doi:10.1113/jphysiol.1990.sp018243

20. Pivoriuunas A, Surovas A, Borutinskaite V, Matuzeviccius D, Treigyte G, Savickiene J, Tunaitis V, Aldonyte R, Jarmalavicciuute A, Suriakaite K, Liutkeviccius E, Venalis A, Navakauskas D, Navakauskiene R, Magnusson KE (2010) Proteomic analysis of stromal cells derived from the dental pulp of human exfoliated deciduous teeth. Stem Cells Dev 19 (7):1081-1093.

doi:10.1089/scd.2009.0315

21. Munoz SS, Engel M, Balez R, Do-Ha D, Cabral-da-Silva MC, Hernandez D, Berg T, Fifita JA, Grima N, Yang S, Blair IP, Nicholson G, Cook AL, Hewitt AW, Pebay A, Ooi L (2020) A Simple Differentiation Protocol for Generation of Induced Pluripotent Stem Cell-Derived Basal ForebrainLike Cholinergic Neurons for Alzheimer's Disease and Frontotemporal Dementia Disease Modeling. Cells 9 (9). doi:10.3390/cells9092018

22. Srinivasan B, Kolli AR, Esch MB, Abaci HE, Shuler ML, Hickman JJ (2015) TEER measurement techniques for in vitro barrier model systems. J Lab Autom 20 (2):107-126. doi:10.1177/2211068214561025 
23. Oladipupo SS, Smith C, Santeford A, Park C, Sene A, Wiley LA, Osei-Owusu P, Hsu J, Zapata N, Liu F, Nakamura R, Lavine KJ, Blumer KJ, Choi K, Apte RS, Ornitz DM (2014) Endothelial cell FGF signaling is required for injury response but not for vascular homeostasis. Proc Natl Acad Sci U S A 111 (37):13379-13384. doi:10.1073/pnas.1324235111

24. Baron O, Ratzka A, Grothe C (2012) Fibroblast growth factor 2 regulates adequate nigrostriatal pathway formation in mice. J Comp Neurol 520 (17):3949-3961. doi:10.1002/cne.23138

25. Woodbury ME, Ikezu T (2014) Fibroblast growth factor-2 signaling in neurogenesis and neurodegeneration. J Neuroimmune Pharmacol 9 (2):92-101. doi:10.1007/s11481-013-9501-5 26. Wang ZG, Cheng Y, Yu XC, Ye LB, Xia QH, Johnson NR, Wei X, Chen DQ, Cao G, Fu XB, Li XK, Zhang HY, Xiao J (2016) bFGF Protects Against Blood-Brain Barrier Damage Through Junction Protein Regulation via PI3K-Akt-Rac1 Pathway Following Traumatic Brain Injury. Mol Neurobiol 53 (10):7298-7311. doi:10.1007/s12035-015-9583-6

27. Lin L, Wang Q, Qian K, Cao Z, Xiao J, Wang X, Li X, Yu Z (2018) bFGF Protects Against Oxygen Glucose Deprivation/Reoxygenation-Induced Endothelial Monolayer Permeability via S1PR1-Dependent Mechanisms. Mol Neurobiol 55 (4):3131-3142. doi:10.1007/s12035-017-0544-0 28. Chen P, Zhang H, Zhang Q, Zhou W, Deng Y, Hu X, Zhang L (2019) Basic Fibroblast Growth Factor Reduces Permeability and Apoptosis of Human Brain Microvascular Endothelial Cells in Response to Oxygen and Glucose Deprivation Followed by Reoxygenation via the Fibroblast Growth Factor Receptor 1 (FGFR1)/ERK Pathway. Med Sci Monit 25:7191-7201. doi:10.12659/MSM.918626

29. Linville RM, DeStefano JG, Sklar MB, Chu C, Walczak P, Searson PC (2020) Modeling hyperosmotic blood-brain barrier opening within human tissue-engineered in vitro brain microvessels. J Cereb Blood Flow Metab 40 (7):1517-1532. doi:10.1177/0271678X19867980 30. Katt ME, Xu ZS, Gerecht S, Searson PC (2016) Human Brain Microvascular Endothelial Cells Derived from the BC1 iPS Cell Line Exhibit a Blood-Brain Barrier Phenotype. PLoS One 11 (4):e0152105. doi:10.1371/journal.pone.0152105

31. Bauer H, Zweimueller-Mayer J, Steinbacher P, Lametschwandtner A, Bauer HC (2010) The dual role of zonula occludens (ZO) proteins. J Biomed Biotechnol 2010:402593.

doi: $10.1155 / 2010 / 402593$

32. Gottardi CJ, Arpin M, Fanning AS, Louvard D (1996) The junction-associated protein, zonula occludens-1, localizes to the nucleus before the maturation and during the remodeling of cell-cell contacts. Proc Natl Acad Sci U S A 93 (20):10779-10784. doi:10.1073/pnas.93.20.10779

33. Islas S, Vega J, Ponce L, Gonzalez-Mariscal L (2002) Nuclear localization of the tight junction protein ZO-2 in epithelial cells. Exp Cell Res 274 (1):138-148. doi:10.1006/excr.2001.5457

34. Gao F, Artham S, Sabbineni H, Al-Azayzih A, Peng XD, Hay N, Adams RH, Byzova TV, Somanath PR (2016) Akt1 promotes stimuli-induced endothelial-barrier protection through FoxOmediated tight-junction protein turnover. Cell Mol Life Sci 73 (20):3917-3933. doi:10.1007/s00018016-2232-z

35. Greene C, Hanley N, Campbell M (2019) Claudin-5: gatekeeper of neurological function. Fluids Barriers CNS 16 (1):3. doi:10.1186/s12987-019-0123-Z

36. Leclair HM, Andre-Gregoire G, Treps L, Azzi S, Bidere N, Gavard J (2016) The E3 ubiquitin ligase MARCH3 controls the endothelial barrier. FEBS Lett 590 (20):3660-3668.

doi:10.1002/1873-3468.12417

37. Ornitz DM, Itoh N (2015) The Fibroblast Growth Factor signaling pathway. Wiley Interdiscip Rev Dev Biol 4 (3):215-266. doi:10.1002/wdev.176

38. Kim S, Ahn C, Bong N, Choe S, Lee DK (2015) Biphasic effects of FGF2 on adipogenesis. PLoS One 10 (3):e0120073. doi:10.1371/journal.pone.0120073

39. Santhana Kumar K, Neve A, Guerreiro Stucklin AS, Kuzan-Fischer CM, Rushing EJ, Taylor MD, Tripolitsioti D, Behrmann L, Kirschenbaum D, Grotzer MA, Baumgartner M (2018) TGF-beta Determines the Pro-migratory Potential of bFGF Signaling in Medulloblastoma. Cell Rep 23 (13):3798-3812 e3798. doi:10.1016/j.celrep.2018.05.083

40. Presta M, Andres G, Leali D, Dell'Era P, Ronca R (2009) Inflammatory cells and chemokines sustain FGF2-induced angiogenesis. Eur Cytokine Netw 20 (2):39-50. doi:10.1684/ecn.2009.0155 41. Nakamura K, Arimura K, Nishimura A, Tachibana M, Yoshikawa Y, Makihara N, Wakisaka Y, Kuroda J, Kamouchi M, Ooboshi H, Kitazono T, Ago T (2016) Possible involvement of basic FGF in the upregulation of PDGFRbeta in pericytes after ischemic stroke. Brain Res 1630:98-108. doi:10.1016/j.brainres.2015.11.003 
42. Shimizu F, Sano Y, Abe MA, Maeda T, Ohtsuki S, Terasaki T, Kanda T (2011) Peripheral nerve pericytes modify the blood-nerve barrier function and tight junctional molecules through the secretion of various soluble factors. J Cell Physiol 226 (1):255-266. doi:10.1002/jcp.22337 43. Sengul B, Dursun E, Verkhratsky A, Gezen-Ak D (2021) Overexpression of alpha-Synuclein Reorganises Growth Factor Profile of Human Astrocytes. Mol Neurobiol 58 (1):184-203. doi:10.1007/s12035-020-02114-x

44. Linnerbauer M, Rothhammer V (2020) Protective Functions of Reactive Astrocytes Following Central Nervous System Insult. Front Immunol 11:573256. doi:10.3389/fimmu.2020.573256

45. Kirby ED, Muroy SE, Sun WG, Covarrubias D, Leong MJ, Barchas LA, Kaufer D (2013) Acute stress enhances adult rat hippocampal neurogenesis and activation of newborn neurons via secreted astrocytic FGF2. Elife 2:e00362. doi:10.7554/eLife.00362

46. Messersmith DJ, Murtie JC, Le TQ, Frost EE, Armstrong RC (2000) Fibroblast growth factor 2 (FGF2) and FGF receptor expression in an experimental demyelinating disease with extensive remyelination. J Neurosci Res 62 (2):241-256. doi:10.1002/1097-4547(20001015)62:2<241::AIDJNR9>3.0.CO;2-D 
a

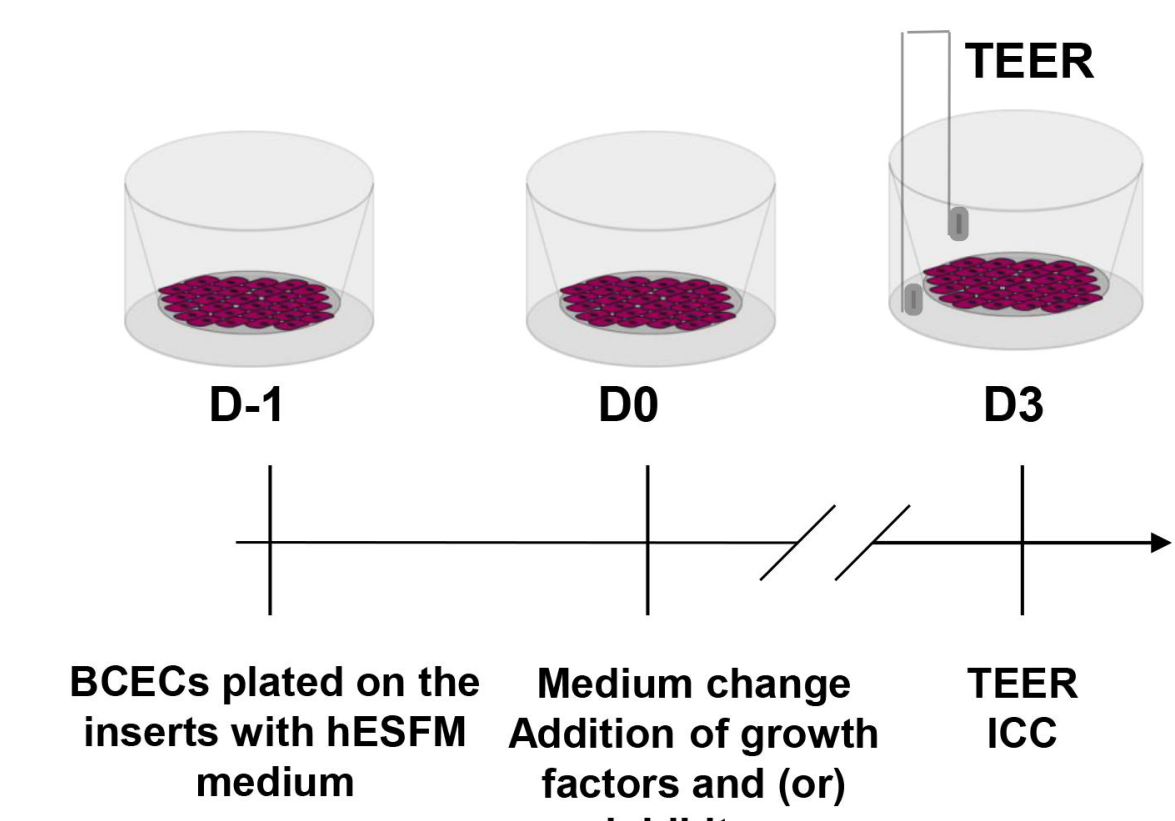
medium factors and (or) inhibitors

d

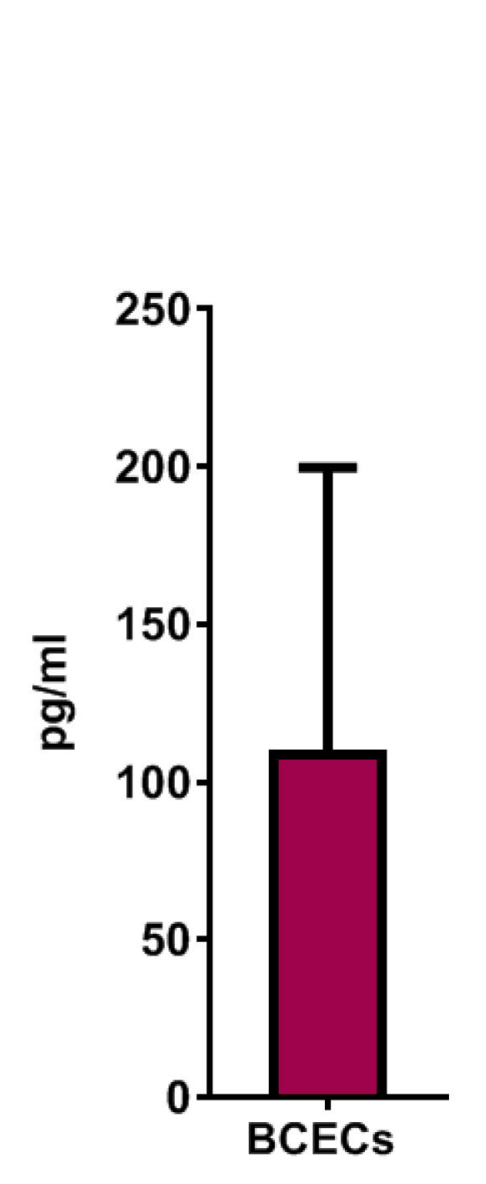

e b

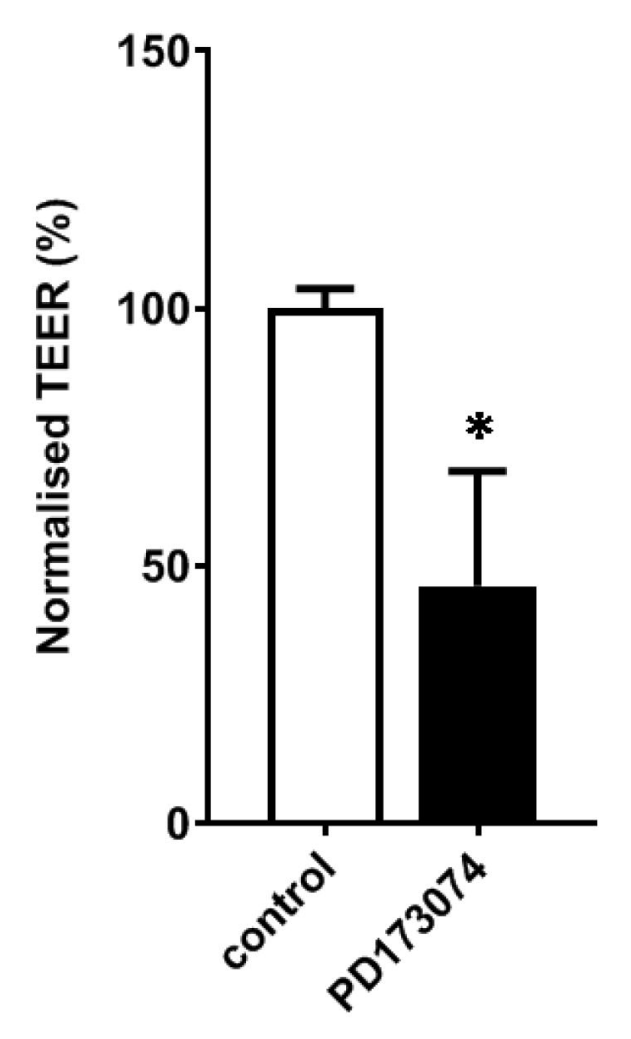

C

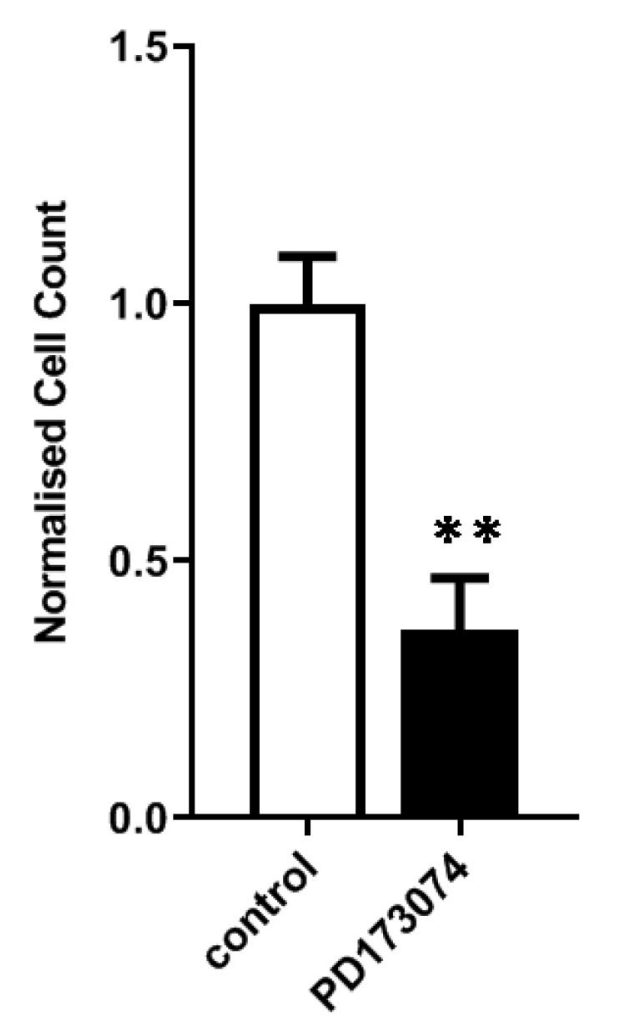

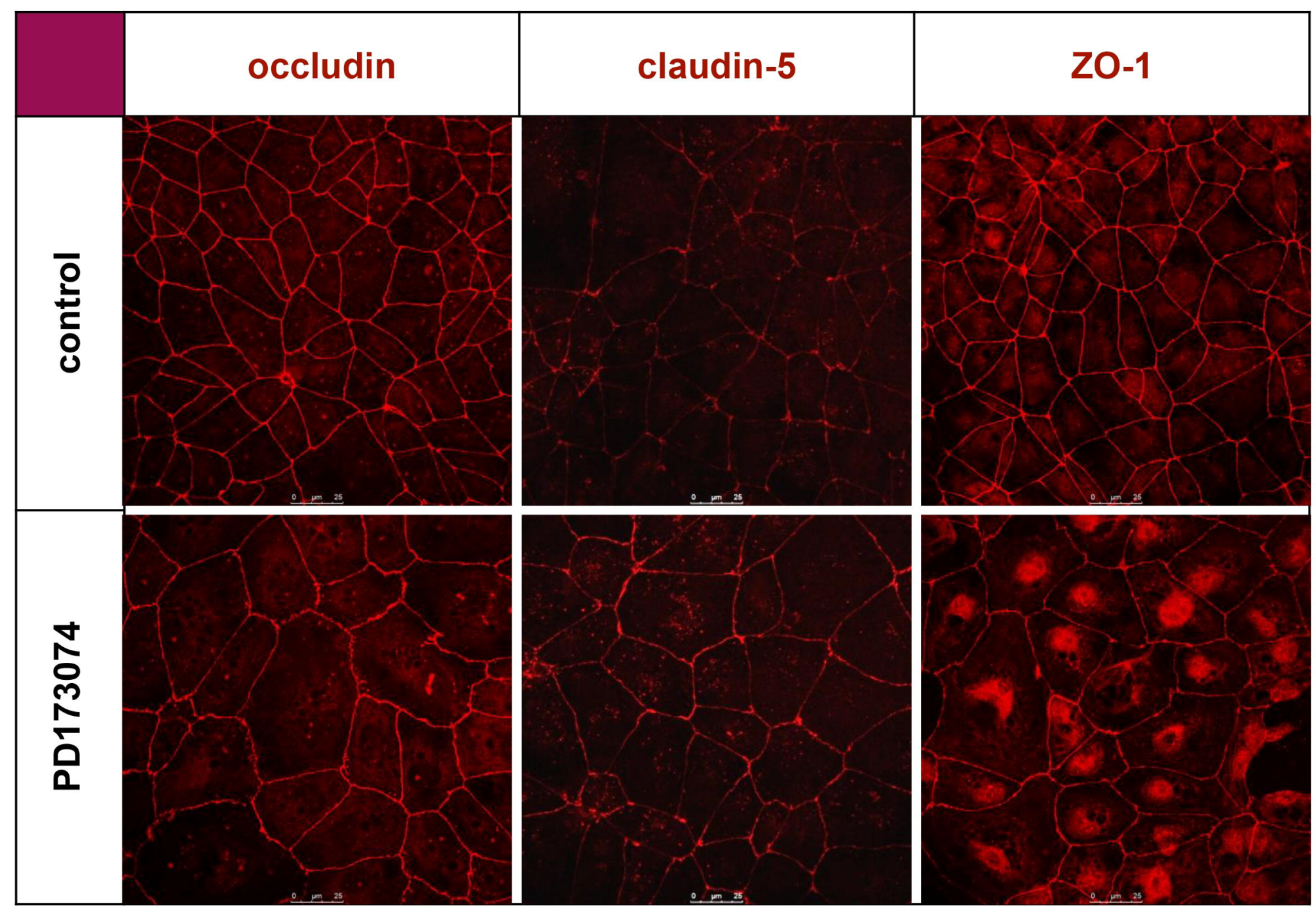



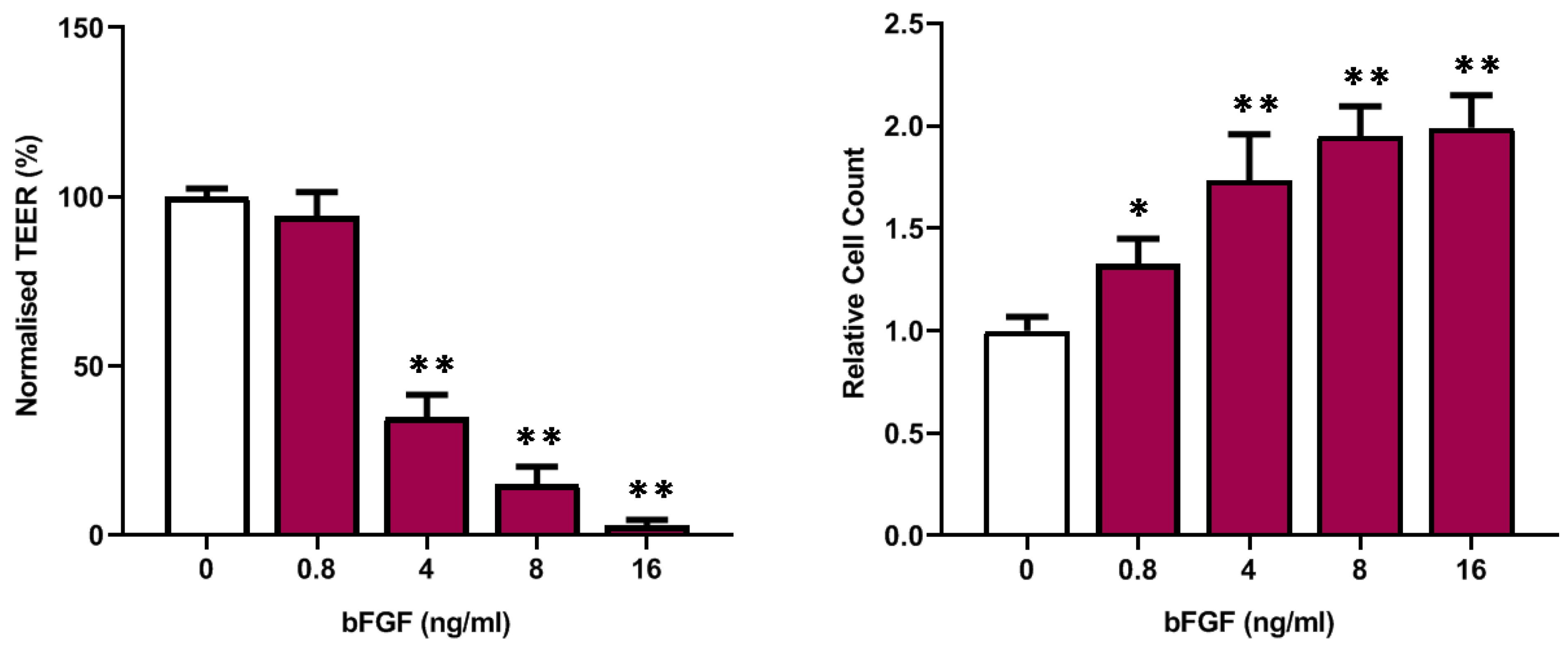
a

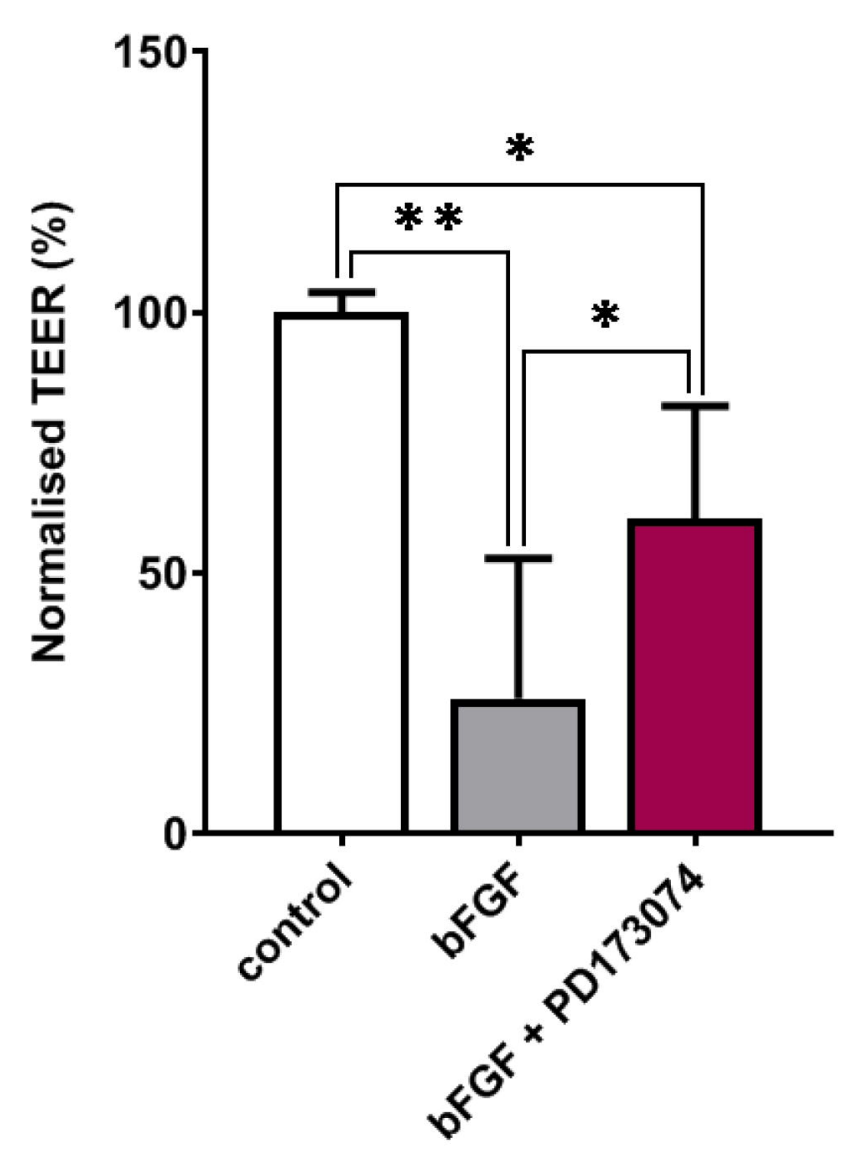

b

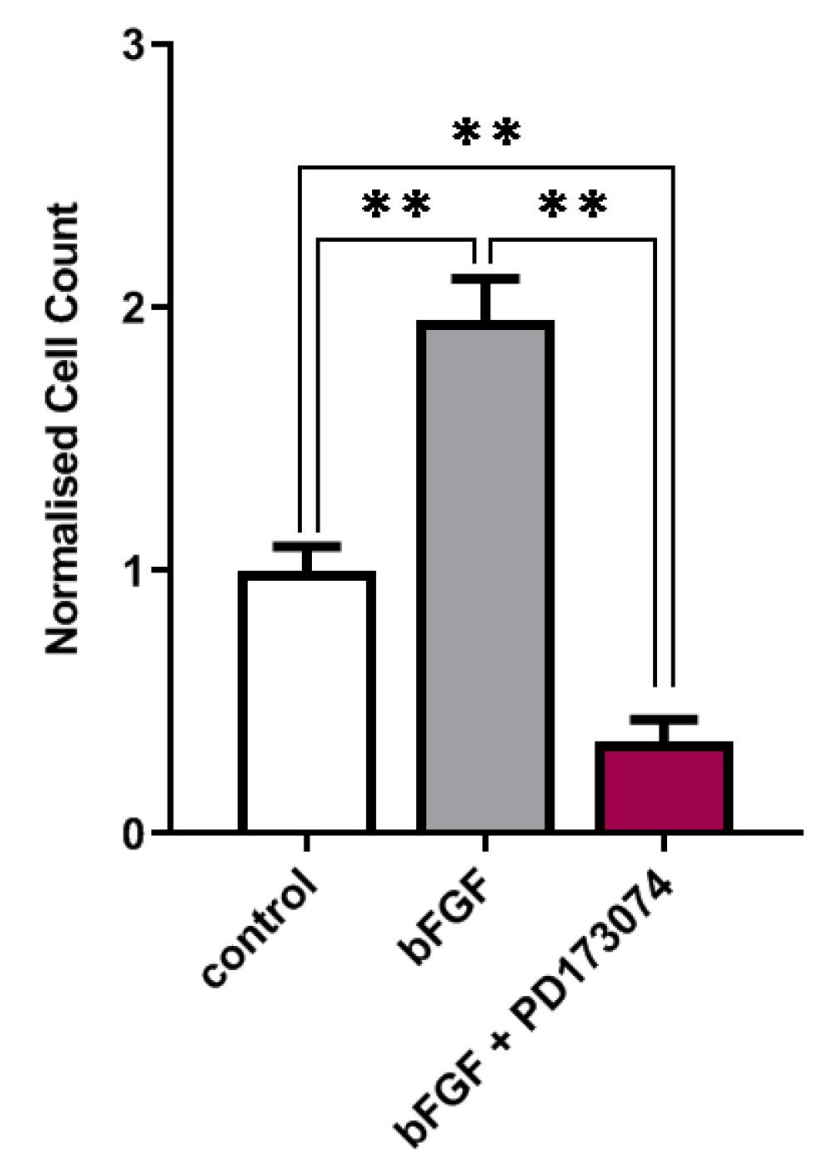

C

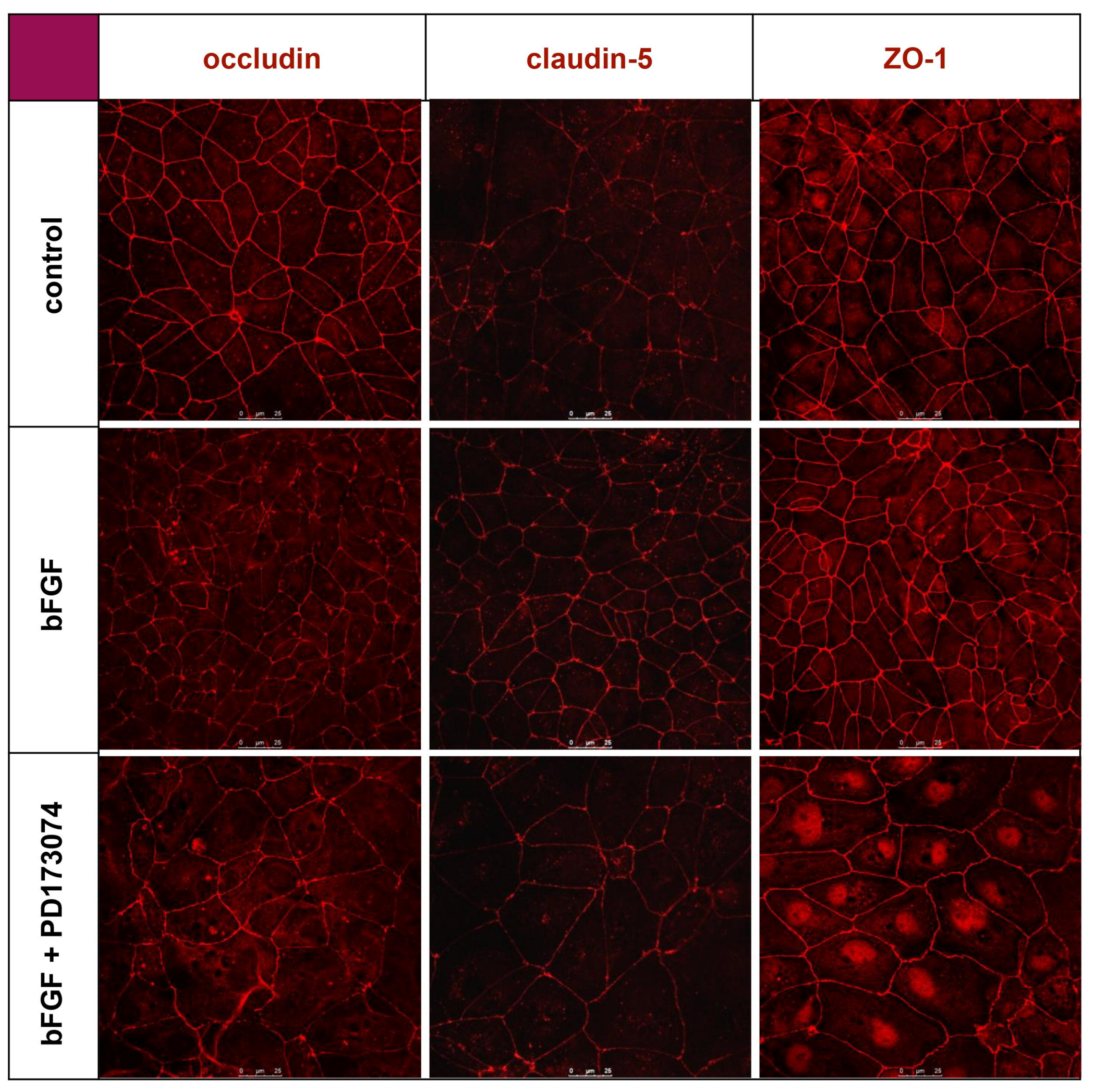




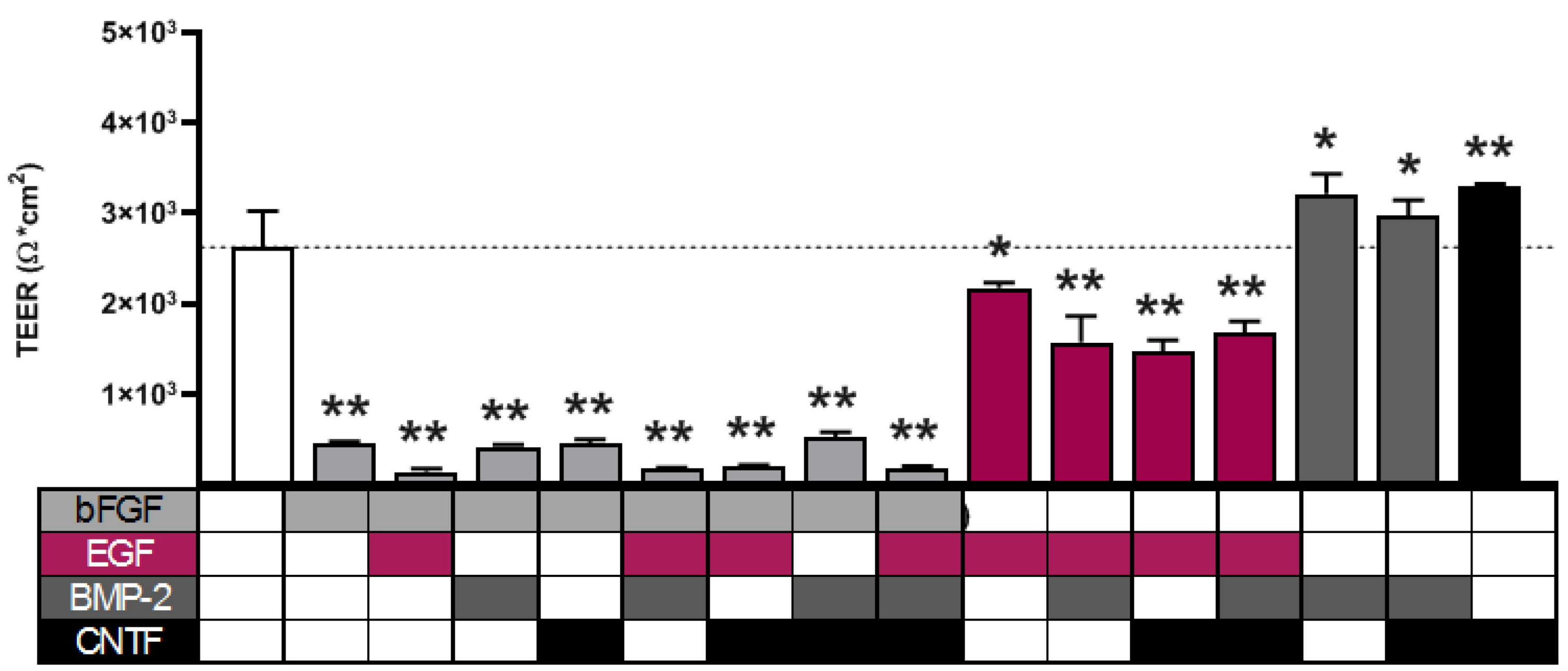

b

\begin{tabular}{|c|c|c|c|c|c|c|c|c|c|c|c|c|c|c|c|c|}
\hline \multicolumn{17}{|l|}{ bFGF } \\
\hline \multicolumn{17}{|l|}{ EGF } \\
\hline \multicolumn{17}{|l|}{ BMP-2 } \\
\hline \multicolumn{17}{|l|}{ CNTF } \\
\hline $\mathbf{n}$ & 3 & 3 & 3 & 3 & 3 & 3 & 3 & 3 & 3 & 3 & 2 & 3 & 3 & 2 & 3 & 3 \\
\hline mean & 2623.00 & 467.10 & 144.40 & 145.80 & 454.10 & 182.40 & 203.40 & 530.70 & 188.10 & 2176.00 & 1572.00 & 1472.00 & 1684.00 & 3213.00 & 2978.00 & 3288.00 \\
\hline $\pm S D$ & 399.60 & 6.47 & 29.68 & 28.04 & 47.91 & 9.30 & 15.90 & 50.00 & 18.37 & 54.67 & 294.60 & 128.30 & 119.80 & 219.70 & 166.70 & 36.13 \\
\hline$p$ value & - & $<0.0001$ & $<0.0001$ & $<0.0001$ & $<0.0001$ & $<0.0001$ & $<0.0001$ & $<0.0001$ & $<0.0001$ & 0.006 & $<0.0001$ & $<0.0001$ & $<0.0001$ & 0.0009 & 0.0426 & $<0.0001$ \\
\hline
\end{tabular}


a

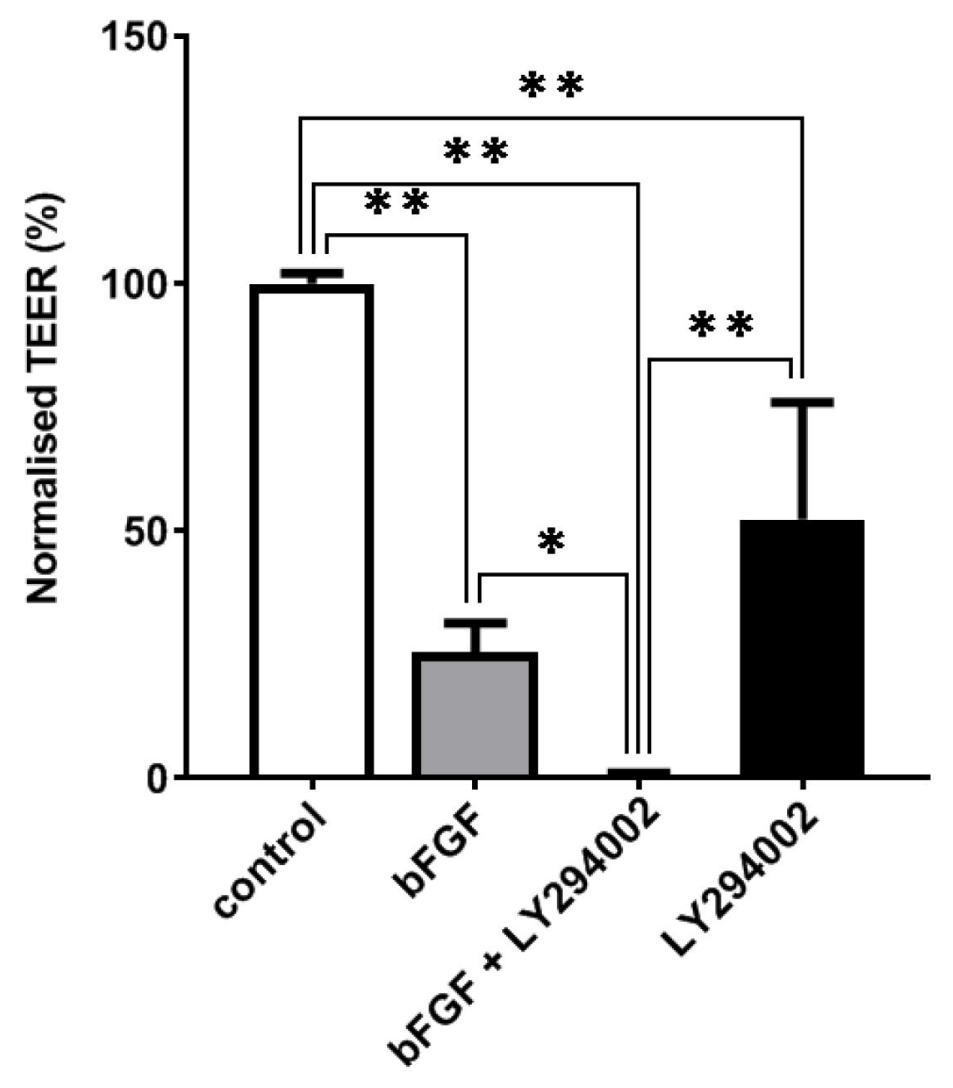

b

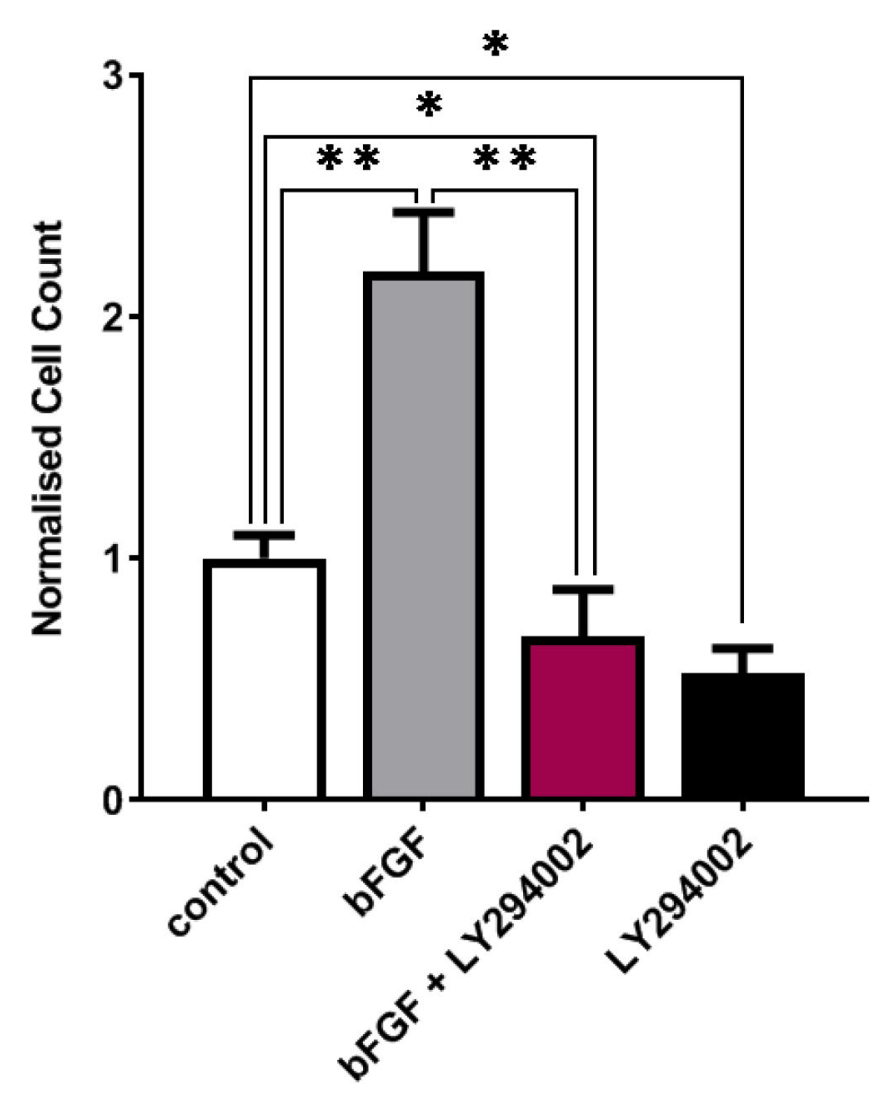

occludin

claudin-5

ZO-1 
a

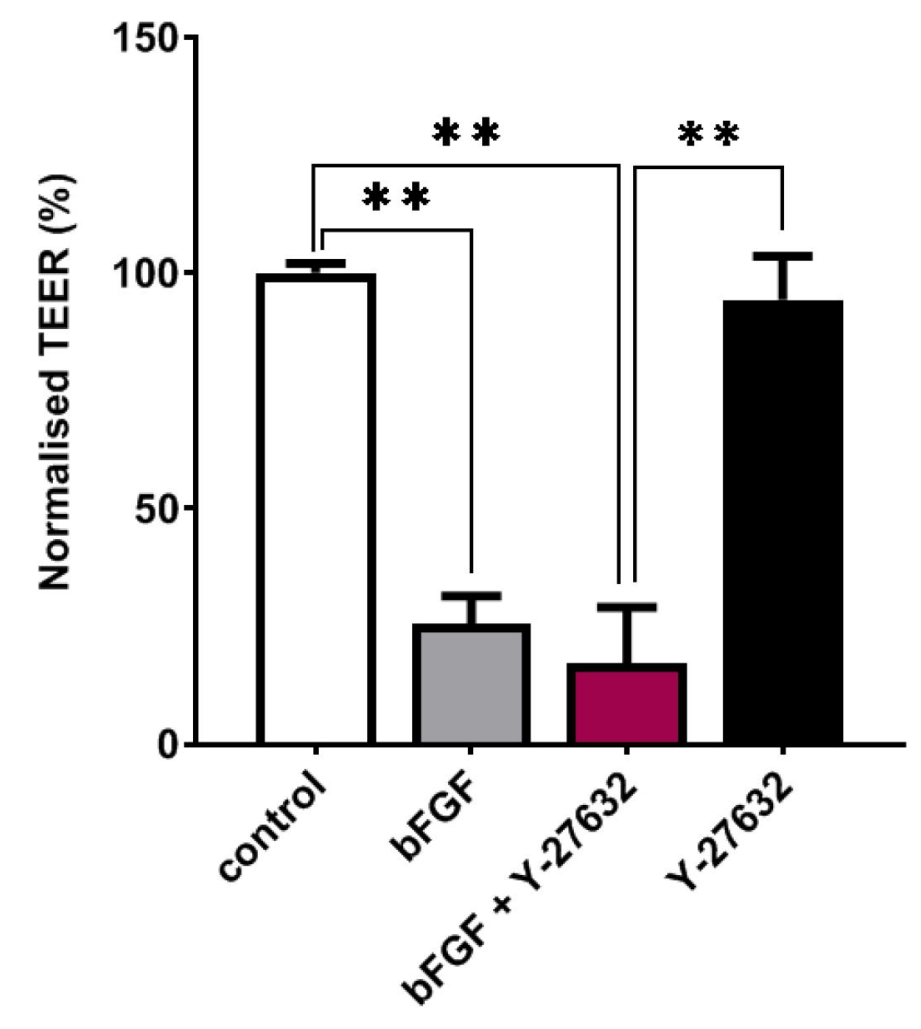

b

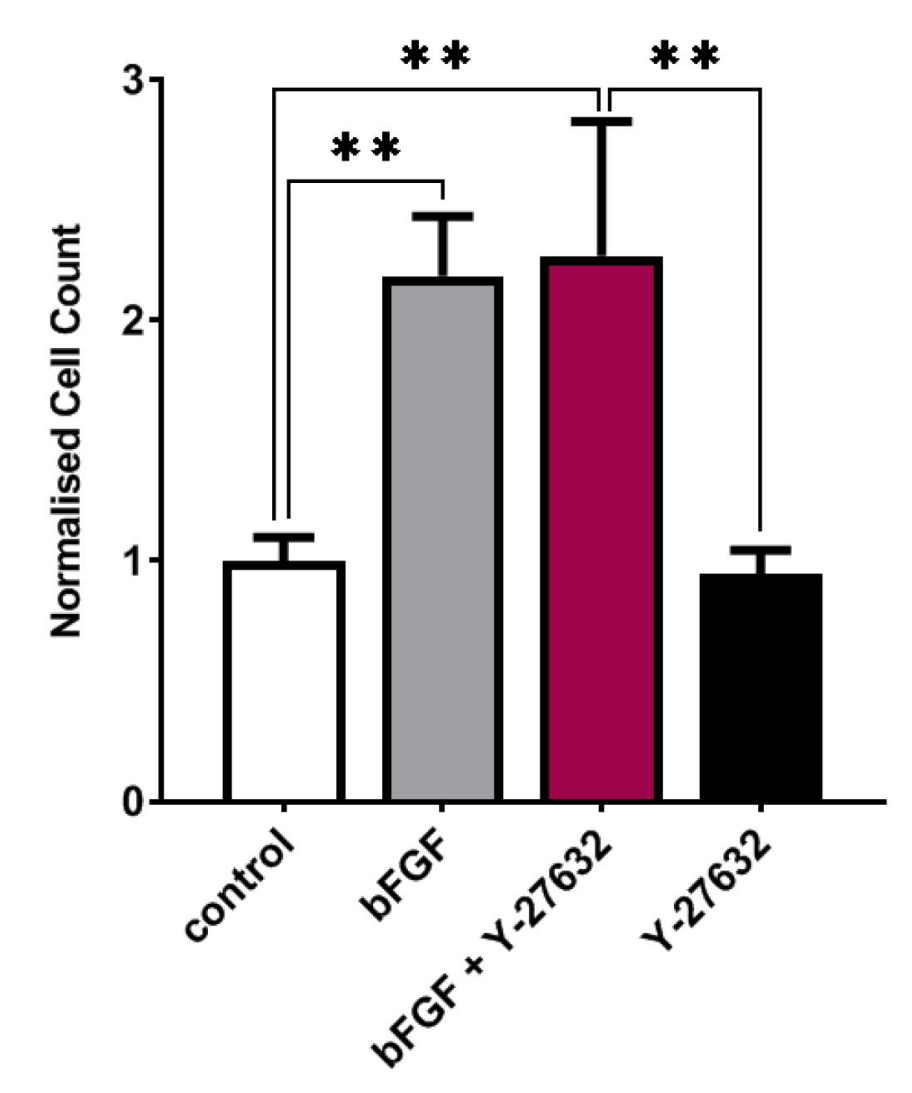

C

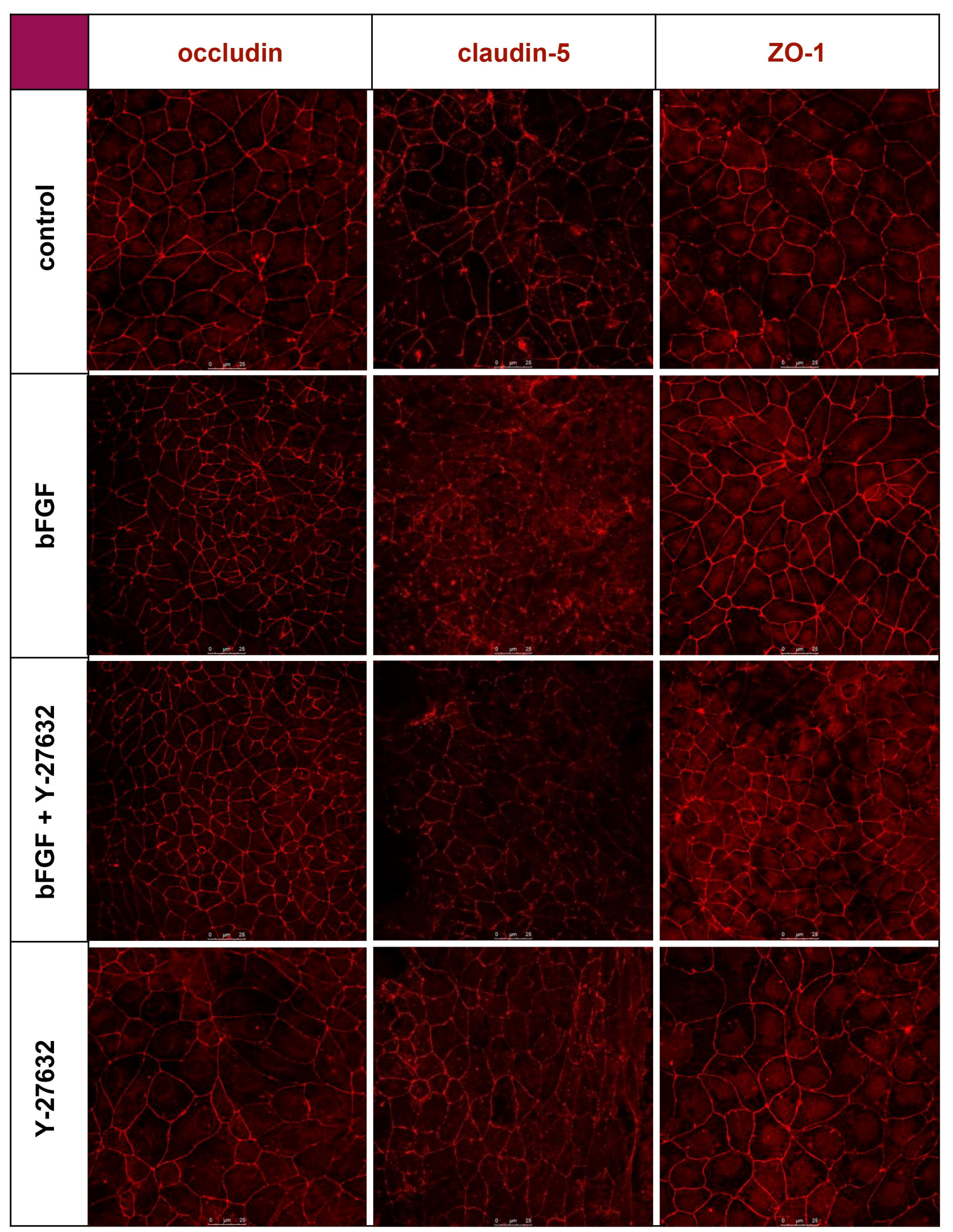




\begin{tabular}{|c|c|c|c|c|c|}
\hline control & bFGF & bFGF + Y-27632 & Y-27632 & bFGF + LY294002 & LY294002 \\
\hline & & & & & \\
& & & & & \\
& & & & & \\
& & & & & \\
\hline
\end{tabular}


Autocrine
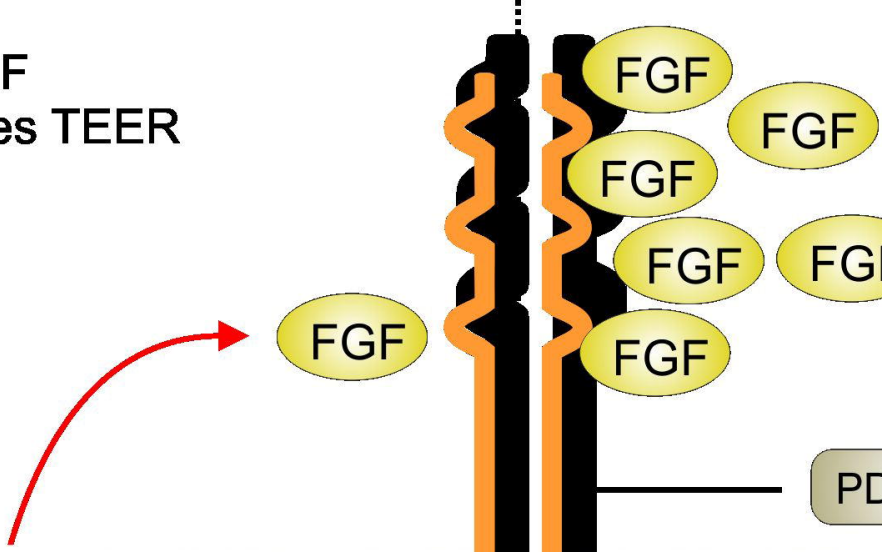

FGF

PD173074

FGF
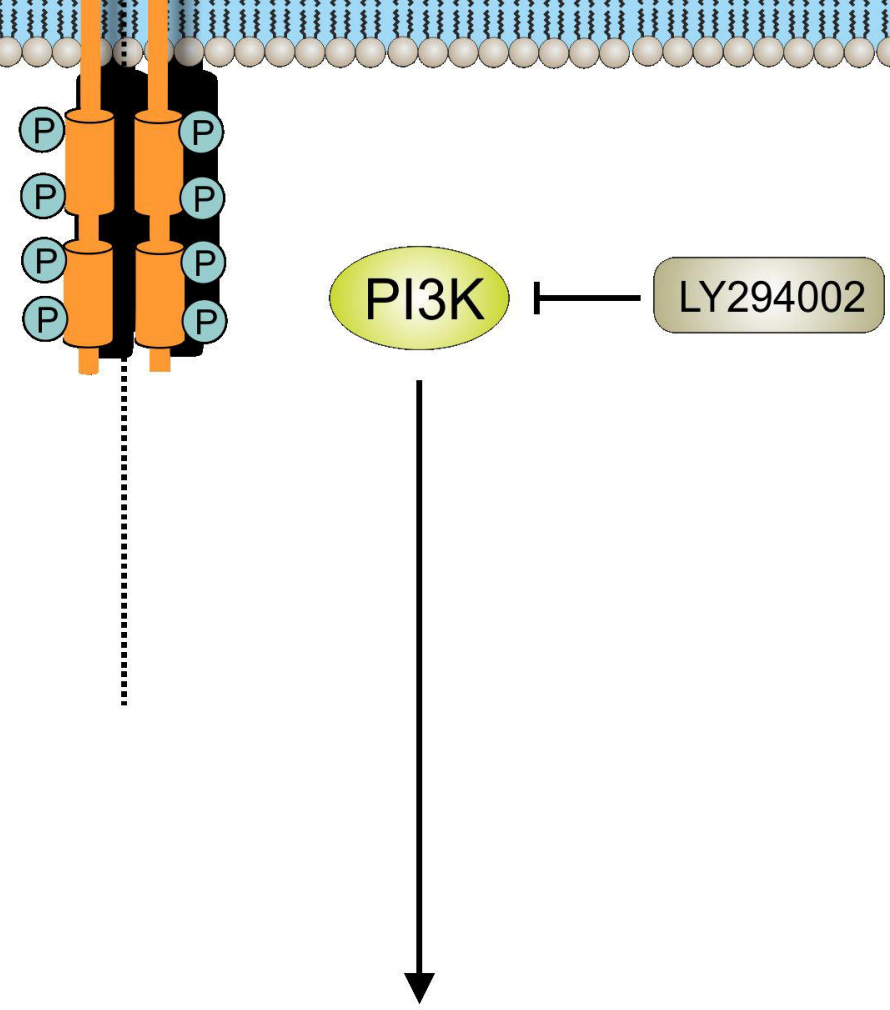

Up-regulation of the barrier function 